Research Article

\title{
Characteristics and Time-Space Evolution of Mining Stress in High Stope
}

\author{
Yongyue Hu $\mathbb{D}^{1,2}$ Jingjie Zhang ${ }^{1},{ }^{3}$ Changhong Li $\left(\mathbb{D},{ }^{1,2}\right.$ Zhengyang Song, ${ }^{1,2}$ \\ Yonggang Xiao $\mathbb{D}^{1,2,3}$ and Yu Wang $\mathbb{D}^{1,2}$ \\ ${ }^{1}$ School of Civil and Resource Engineering, University of Science and Technology Beijing, Beijing 100083, China \\ ${ }^{2}$ Key Laboratory of Ministry of Education for High-Efficient Mining and Safety of Metal Mines, \\ University of Science and Technology Beijing, Beijing 100083, China \\ ${ }^{3}$ Chengde Petroleum College, Chengde 067000, Hebei, China
}

Correspondence should be addressed to Jingjie Zhang; zhangjingjienice@163.com and Yu Wang; wyzhou@ustb.edu.cn

Received 13 April 2021; Accepted 13 May 2021; Published 24 May 2021

Academic Editor: Xianjie Hao

Copyright (C) 2021 Yongyue Hu et al. This is an open access article distributed under the Creative Commons Attribution License, which permits unrestricted use, distribution, and reproduction in any medium, provided the original work is properly cited.

Due to the lack of relevant investigation research on the evolution of mining stress in high stope of metal mines, the understanding of how to ensure the safety during mining process is not clear at all. In this paper, by monitoring the mining-induced pressure of the surrounding rock in the 16-2 $2^{\#}$ stope of Lilou Iron Mine, the evolution of the mining-induced pressure of the subsequent filling and mining method of the high-stage empty field is obtained. The study shows that there are three stages of pressure change in the second-step stope of Lilou Iron Mine: I (stress rising stage), II (stable stage), and III (pressure relief stage), and the mining stress in the surrounding rock is transferred from the top to bottom. The stress transfer model of stope is proposed, and the variation of vertical stress versus the depth is fitted; the four horizontal sections are fitted, respectively. By establishing the three-dimensional numerical model and distributed excavation simulation, the time-space evolution of mining stress is obtained and compared with the in-site measuring result. The two results show high consistency, and the effectiveness of numerical simulation is verified.

\section{Introduction}

The stress disturbance of surrounding rock based on the original rock stress state is the direct factor causing the instability and failure of the project, and the mining stress accompanying the mining process of the ore body is an important reason for the failure of the surrounding rock $[1,2]$. With the continuous increase of the mining scale of mines, the stress conditions of the surrounding rock of the roadway are becoming more complicated $[3,4]$, and the problems related to the ground pressure are also becoming more prominent [5]. In the aspects of ore body mining and roadway support, it can be directly guided by the results of mining stress monitoring to ensure the safety of production [6]. For a long time, some research results about the mining stress distribution characteristics and migration law of surrounding rock have been studied by many scholars $[7,8]$. The field stress measurement technology based on hollow envelope strain gauge is used to monitor the stress during TBM tunnel construction of the diversion tunnel of Jinping II hydropower station, and the stress evolution characteristics of field monitoring are obtained [9]. By using a longterm stress monitoring system based on the digital CSIRO dual temperature compensation method, the effective monitoring of rock mining stress is realized, and the stress evolution law in the whole mining process is obtained [10]. By studying the abutment pressure changes around the stope, the distribution range, peak value, and spatial position of advanced abutment pressure are analyzed [11-13]. According to the space-time evolution law of three-dimensional stress of the floor and the stress of supporting structure, the main reason of roadway segmental failure and repeated failure is the space-time corresponding relationship of the surrounding rock deformation area [14-17]. According to the evolution law of mining dynamics under different mining conditions, the mining dynamic characteristics of the peak value and 
position of rock mass support pressure in front of the working face under the influence of mining are obtained [18, 19]. Based on the study of three-dimensional mining stress variation law and overburden failure and instability process in deep stope, the action mechanism of vertical stress and horizontal stress in overburden fracture and instability process is mastered $[20,21]$. Based on the movement state of thick and hard rock strata, the stress transfer model of stope is established [22].

Most of the research studies focus on the law of mining stress evolution in coal mines. However, the effective monitoring methods and theoretical basis of mining stress in high stope of metal mines are a lack of research [23, 24], and generally, metal mines can only make simple assumptions and analysis based on experience or engineering analogy, which has certain blindness. Therefore, based on the previous research and the engineering background of Lilou Iron Mine, a new stress monitoring system is used to monitor the stope in real time, and the three-dimensional stress evolution of the surrounding rock in the whole mining process is obtained. Compared with the numerical simulation, the reliability of the monitoring method is verified, which is of great significance for revealing the dynamic disaster mechanism of surrounding rock in metal mines.

\section{Monitoring System and Layout of Measuring Points of Stope Mining Stress}

2.1. Mining Stress Monitoring System. As shown in Figure 1, the stress monitoring system is composed of stress monitoring, data acquisition, and data processing. The self-made long-term stress monitoring system for underground cavern mining is mainly used for stress monitoring. The working temperature range is $0^{\circ} \mathrm{C}-60^{\circ} \mathrm{C}$, the resistance value of the strain gauge is $120 \Omega$, the measurement accuracy is $\pm 10 \mathrm{ppm}$, Bluetooth signal communication is adopted, and the waterproof and moisture-proof battery is continuously powered. The data acquisition format is NMEA 0183, and the resolution of the instrument is \pm 0.1 microstrain.

\subsection{Working Principle of Mining Stress Monitoring System.} The monitoring system can realize the real-time monitoring of mining stress and automatic data storage, and the stress change in the whole mining process can be fully reflected. Combined with the actual mining process, this instrument is set to collect data every 20 minutes. The main stress measuring instrument of the system is the front-end digital hollow inclusion strain gauge [25], there are three groups of strain gauges in the instrument, each group consists of three circumferential strain gauges and three transverse strain gauges, three parallel measurements are realized, and the measurement error is reduced, as shown in Figure 2, where 1-12 are the strain signal channel and 13-14 are the dual temperature compensation channel.

According to the theory of in situ stress measurement, the stress-strain relationship in each direction is as follows:

$$
\begin{aligned}
\varepsilon_{\theta}= & \frac{1}{E}\left\{\left(\sigma_{x}+\sigma_{y}\right) k_{1}+2\left(1-v^{2}\right)\right. \\
& {\left.\left[\left(\sigma_{y}-\sigma_{x}\right) \cos 2 \theta-2 \tau_{x y} \sin 2 \theta\right] k_{2}-v \sigma_{z} k_{4}\right\}, } \\
\varepsilon_{z}= & \frac{1}{E}\left[\sigma_{z}-v\left(\sigma_{x}+\sigma_{y}\right)\right], \\
\gamma_{\theta z}= & \frac{4}{E}(1+v)\left(\tau_{y z} \cos \theta-\tau_{z x} \sin \theta\right) k_{3}, \\
\mathcal{E}_{ \pm 45^{0}}= & \frac{1}{2}\left(\varepsilon_{\theta}+\varepsilon_{z}+\gamma_{\theta z}\right) .
\end{aligned}
$$

In the formula, $\varepsilon_{\theta}$ is the circumferential strain, $\varepsilon_{z}$ is the axial strain, $\gamma_{\theta z}$ is the shear strain, $k_{1}, k_{2}, k_{3}, k_{4}$ are the correction coefficient, $\sigma_{x}, \sigma_{y}, \sigma_{z}, \tau_{x y}, \tau_{y z}, \tau_{z x}$ are the stress component, $\varepsilon_{ \pm 45^{\circ}}$ is the drilling axis, and $\pm 45^{\circ}$ is the strain value.

The axial strain along the measuring hole can be obtained by measuring the axial strain gauge, and the resultant force along the circumference of the hole can be obtained by adding $0^{\circ}, 120^{\circ}$, and $240^{\circ}$ of the three circumferential strain gauges. The least square method was used to analyze the 3 sets of repeated data obtained by the instrument monitoring. It can be seen from formula (2) that by averaging the three axial strains in the measurement results, the requirements of three parallel measurement tests can be achieved, and the average axial strain formula is obtained [10]:

$$
\varepsilon_{z \text { average }} E \cdot=\sigma_{z}-v\left(\sigma_{x}+\sigma_{y}\right) .
$$

For hoop strain measurement, 3 strain gauges in the same measurement ring are arranged at $0^{\circ}, 120^{\circ}$, and $240^{\circ}$, the measurement results are substituted into formula (5), and the results of the three measurement rings are added together to obtain

$$
\varepsilon_{\theta\left(0^{\circ}\right)}+\varepsilon_{\theta\left(120^{\circ}\right)}+\varepsilon_{\theta\left(240^{\circ}\right)} \cdot E=3\left[\left(\sigma_{x}+\sigma_{y}\right)-v \sigma_{z}\right] .
$$

From formulas (5) and (6), the magnitude of the axial stress $\sigma_{z}$ and the hoop stress level $\left(\sigma_{x}+\sigma_{y}\right)$ can be obtained. Decompose $\left(\sigma_{x}+\sigma_{y}\right)$ according to the plane strain problem, and the three-dimensional stress at the measuring point can be obtained.

2.3. Layout of Stope Monitoring Points. Lilou Iron Mine adopts the high-stage subsequent filling mining method, and the stope is mined to form a substantial mined-out area of nearly $100 \mathrm{~m}, 50 \mathrm{~m}$ wide, and $20 \mathrm{~m}$ long, with a lateral exposed area of $4000 \mathrm{~m}^{2} \sim 6000 \mathrm{~m}^{2}$. At the same time, it is affected by the mechanical effects of gravity, stress release of the surrounding rock of the upper (lower) plate, and the original pillars on both sides and the blasting impact of the stope. With the development of mining, the stress around 


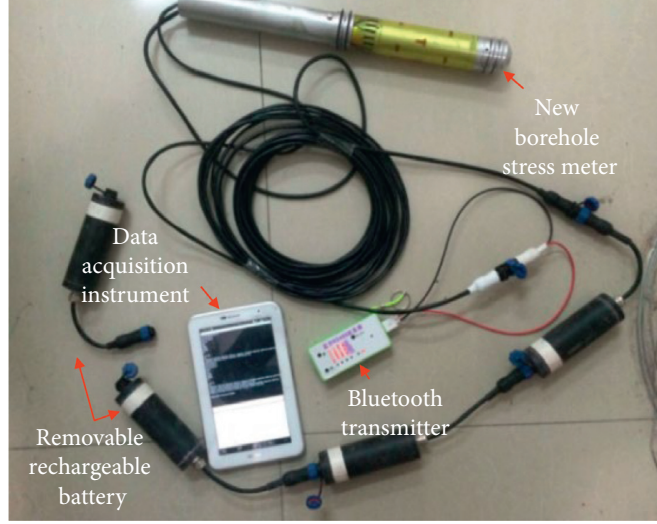

(a)

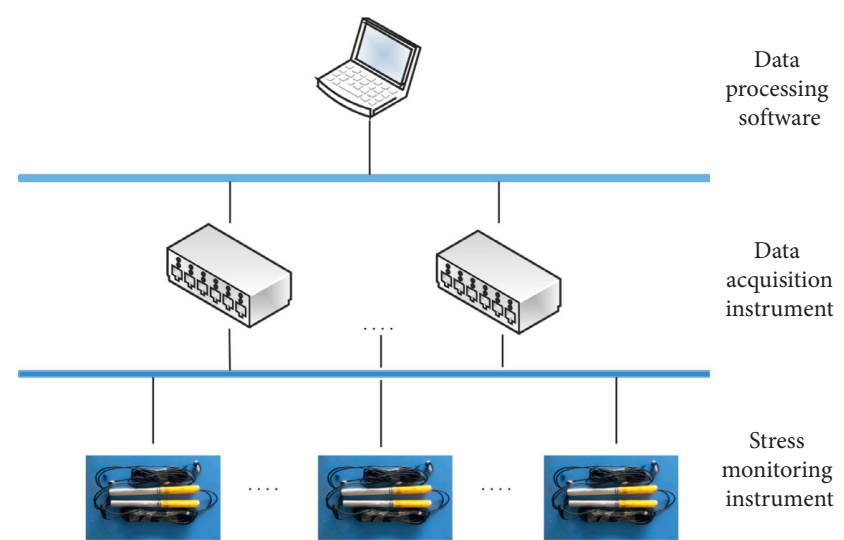

(b)

Figure 1: Mining stress monitoring system.

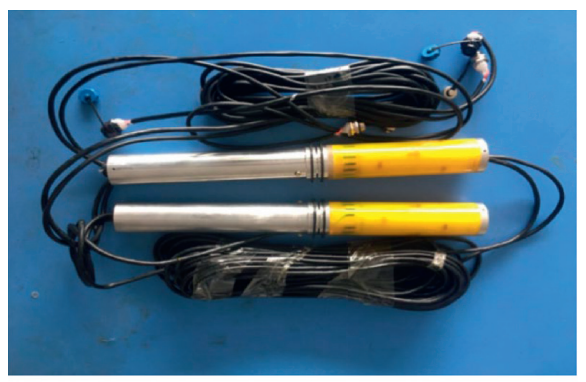

(a)

Top of borehole stress gauge

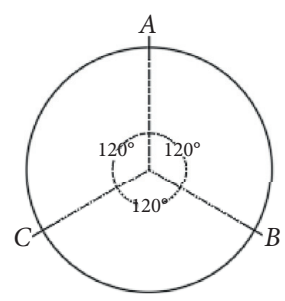

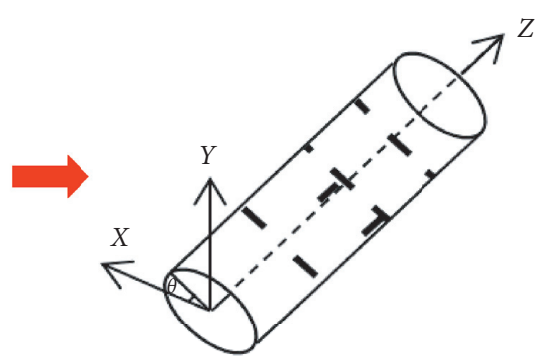

(b)

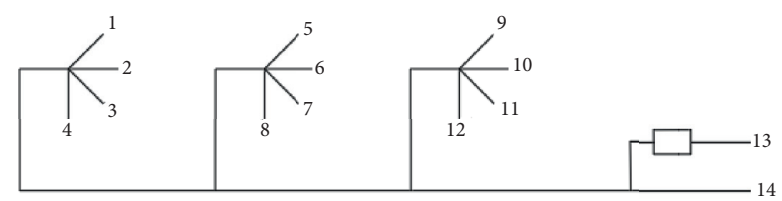

(c)

FIgURE 2: Monitoring probe strain gauge layout plan: (a), (b), and (c) three groups of strain gauges.

the stope is redistributed, which causes stress concentration in some parts and causes a series of ground pressure behavior problems. Such as roof fall and rib spalling, this makes the safety of the surrounding roadway and stope mining and workers' lives and safety are greatly affected.

With the continuous mining of $12-2^{\#}$ stope, $12-6^{\#}$ stope, and $14-4^{\#}$ stope, the roadway in different sections of southern Lilou Iron Mine has been damaged in a large area, and the operation safety of the stope has been seriously affected. Under the condition that the actual production progress of the mine is considered, $16-2^{\#}$ stope is selected to monitor the mining stress, and one monitoring point is arranged in each of the four horizontal drift sections, as shown in Figure 3. The stope is segmented every $20 \mathrm{~m}$ from top to bottom. The cross section size of $-325 \mathrm{~m},-350 \mathrm{~m}$, and $-375 \mathrm{~m}$ horizontal section roadway is $3.8 \mathrm{~m} \times 3.8 \mathrm{~m}$, and the cross section size of $-400 \mathrm{~m}$ horizontal section roadway is
$4.2 \mathrm{~m} \times 4.2 \mathrm{~m}$. The monitoring point is arranged at the entrance of each section of the horizontal roadway. The row of blastholes that is farthest in the horizontal direction is about $35 \mathrm{~m}$ (about 15 rows of blastholes), and the vertical direction is $1.5 \mathrm{~m}$ away from the roadway floor. After the monitoring system is installed, the instrument data must be cleared after each data extraction.

\section{Analysis of Dynamic Evolution of Mining Stress}

3.1. Stress Monitoring Data. The instrument installation and commissioning work are carried out at the four levels of the $16-2^{\#}$ mining area of Lilou Iron Mine, respectively, the monitoring data of stope were selected from September 9, 2017 , to June 4,2018 . The mining stress monitoring system is set to collect data once every 20 minutes, the collected data 


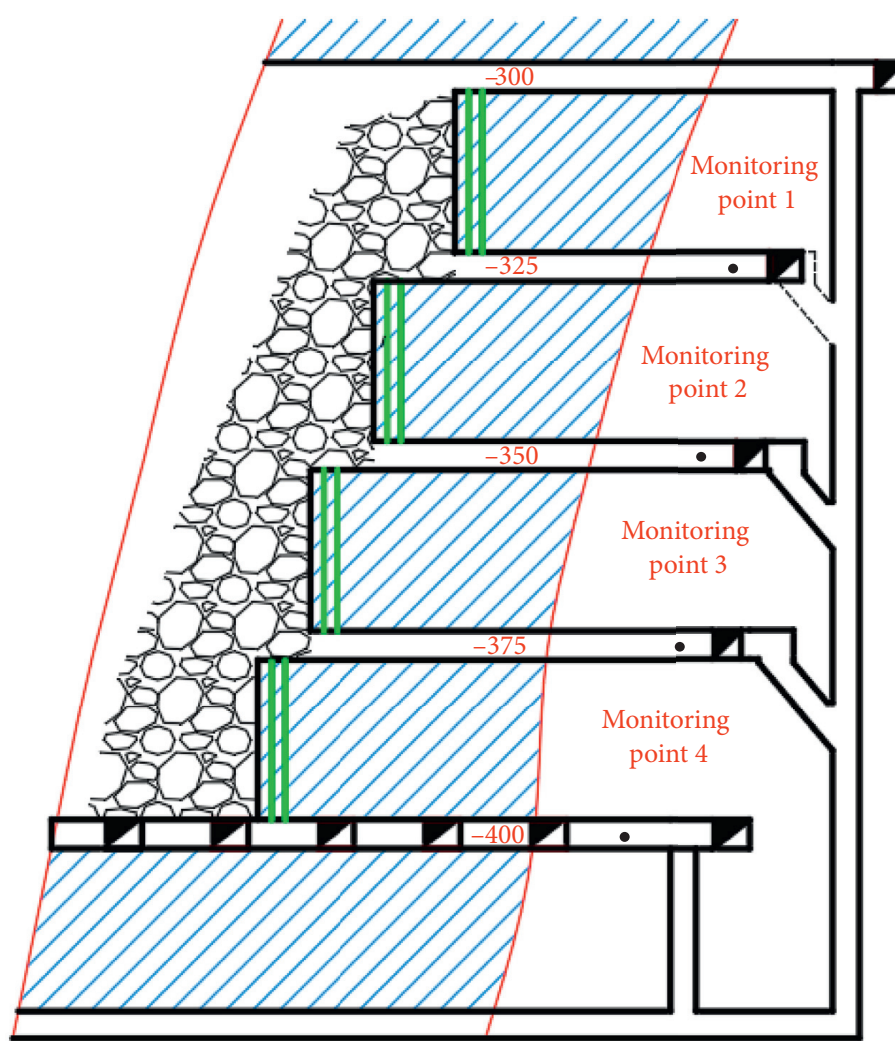

(a)
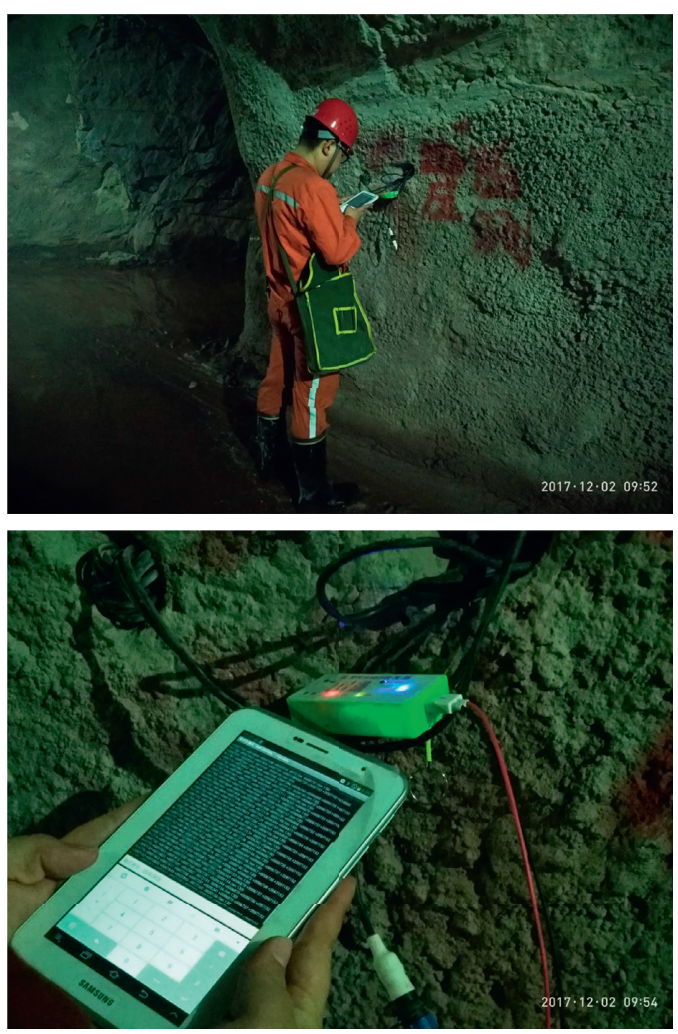

(b)

FIGURE 3: $16-2^{\#}$ stope monitoring point layout and data extraction.

are processed, and the data chart is drawn in days, as shown in Figure 4. By monitoring the disturbance stress in the high stope, the complete dynamic evolution law of the stope ground pressure is obtained. Since the monitoring instrument is installed vertically, the vertical stress is set as $\sigma_{z}$. The transverse horizontal stress is $\sigma_{x}$. The axial horizontal stress is $\sigma_{y}$. The compressive stress is positive, and the tensile stress is negative.

Figure 4 illustrates that in the initial stage of the instrument installation, as the cement gradually solidified, the probe was connected with the rock wall around the hole, under the influence of the original in situ stress of the surrounding rock, the monitoring stress value increased steadily. Five days after the installation of the stress monitoring system, the change value of the vertical stress of the four horizontal sections was the most obvious, reaching 2.6 $\mathrm{MPa}$ on average, while the change of the transverse stress and axial stress was relatively not obvious, this was because the stress on one side of the vertical excavation face has been released, and the instrument bears the influence of the vertical stress. During the whole mining process, the vertical stress, axial stress, and transverse stress have a similar evolution law, the specific performance is that the threedimensional stress peak presents a rising trend, and the stress state of stope surrounding rock is clearly affected by blasting vibration; blasting shock and blasting vibration will make the stress of surrounding rock suddenly increase, but gradually the pressure will transfer to the surrounding rock.
Part of it dissipates. This monitoring work will continue until the completion of the mining operation, and finally the monitoring of mining stress will end at a distance of about $4 \mathrm{~m}$ from the empty area (no monitoring conditions on-site).

In the long-term mining process, it can be seen that the three-dimensional stress values of $-325 \mathrm{~m},-350 \mathrm{~m}$, and $-375 \mathrm{~m}$ horizontal sections are stable, which is the result of stress redistribution after each stope operation. After stress redistribution, the stress value of stope is stable. Affected by far-field operation, the stress value will fluctuate, but it can be ignored. $-400 \mathrm{~m}$ is the horizontal section of ore removal, due to the influence of the overburden above and the selfweight of the collapsed ore body, the stress increases continuously, and the vertical stress change value is about $24 \mathrm{MPa}$, which leads to the continuous development of the surrounding rock cracks and eventually the destruction of surrounding rock, which is consistent with the actual situation. Therefore, in the actual production process of the mine, the damage condition of the surrounding rock at the level of ore drawing section should be checked regularly, and the areas with potential safety hazards should be dealt with in time.

As shown in Figure 5, the monitoring results show that the influence of blasting on the stress change of surrounding rock cannot be ignored. Under the influence of blasting vibration, the stress of surrounding rock jumps up in a short time, and the average horizontal and vertical stresses of the four horizontal sections are 3.67 MPa, 4.34 MPa, 3.35 $\mathrm{MPa}$, 


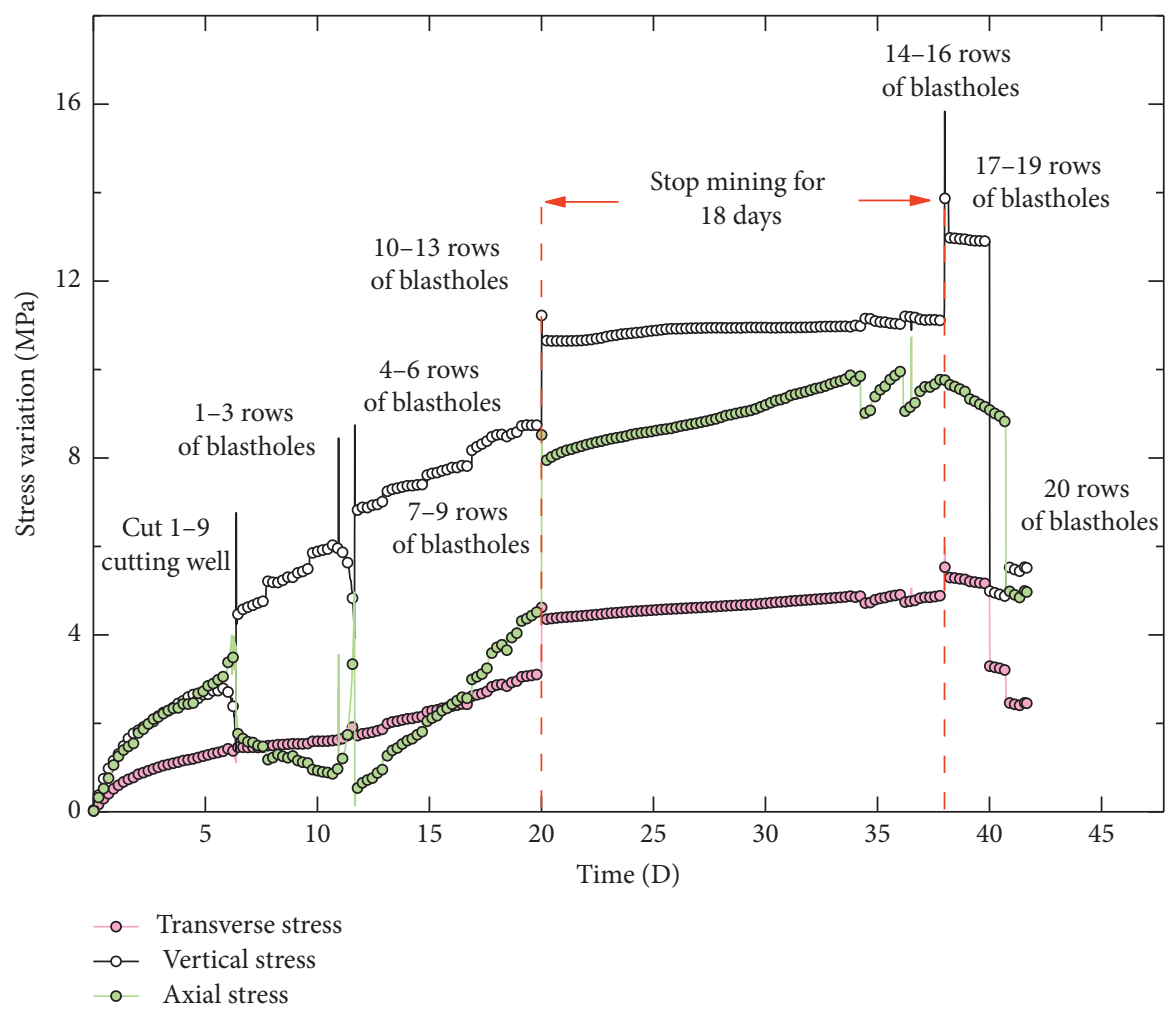

(a)

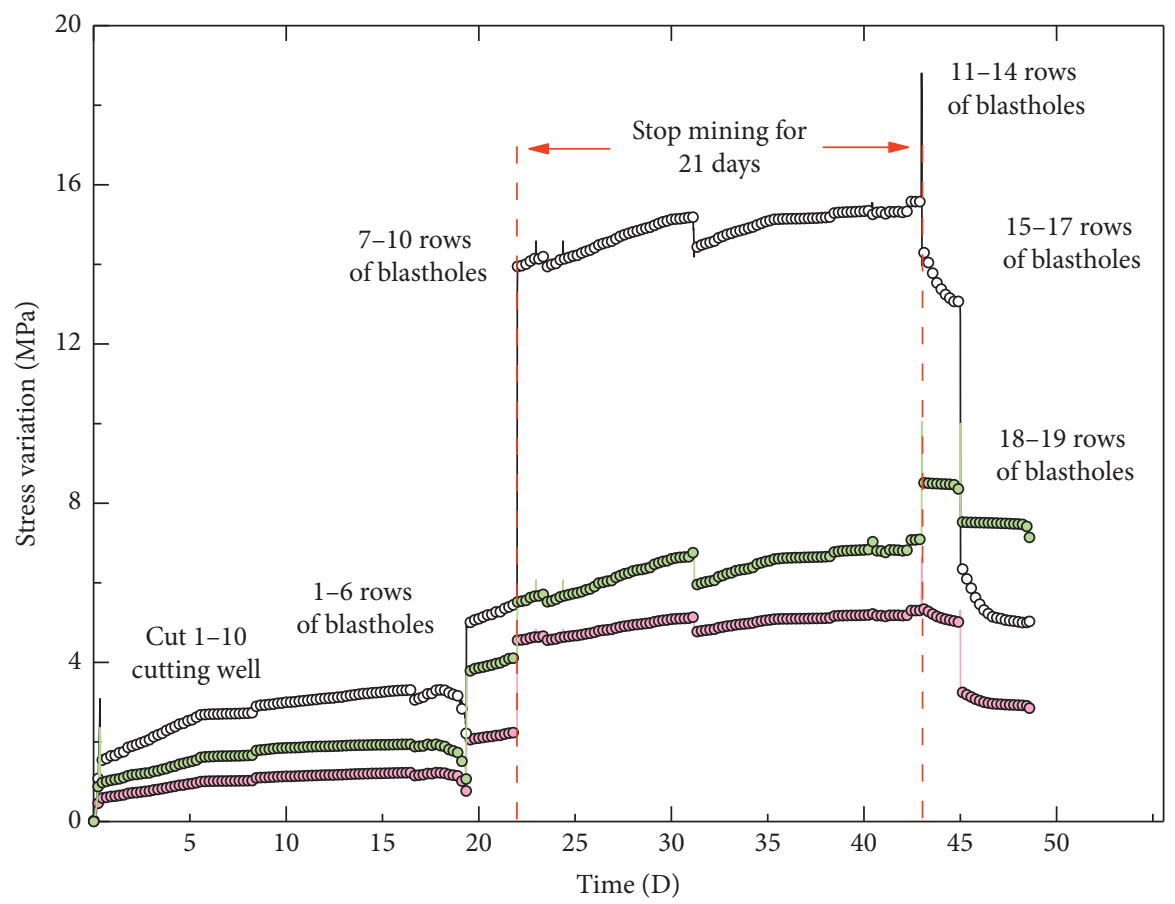

- Transverse stress

$-\infty$ Vertical stress

- Axial stress

(b)

Figure 4: Continued. 


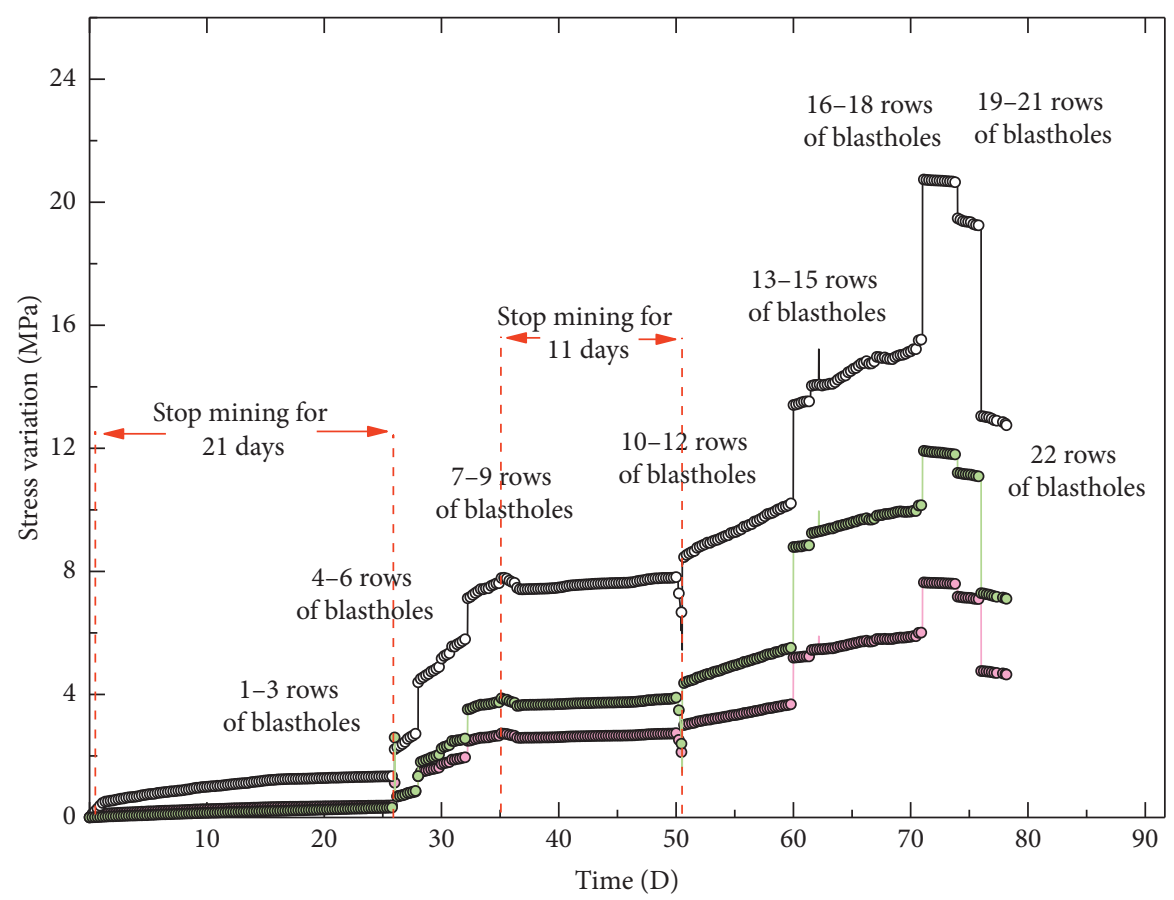

$$
\begin{aligned}
& \text { - Transverse stress } \\
& \text {-0- Vertical stress } \\
& \circ \quad \text { Axial stress }
\end{aligned}
$$

(c)

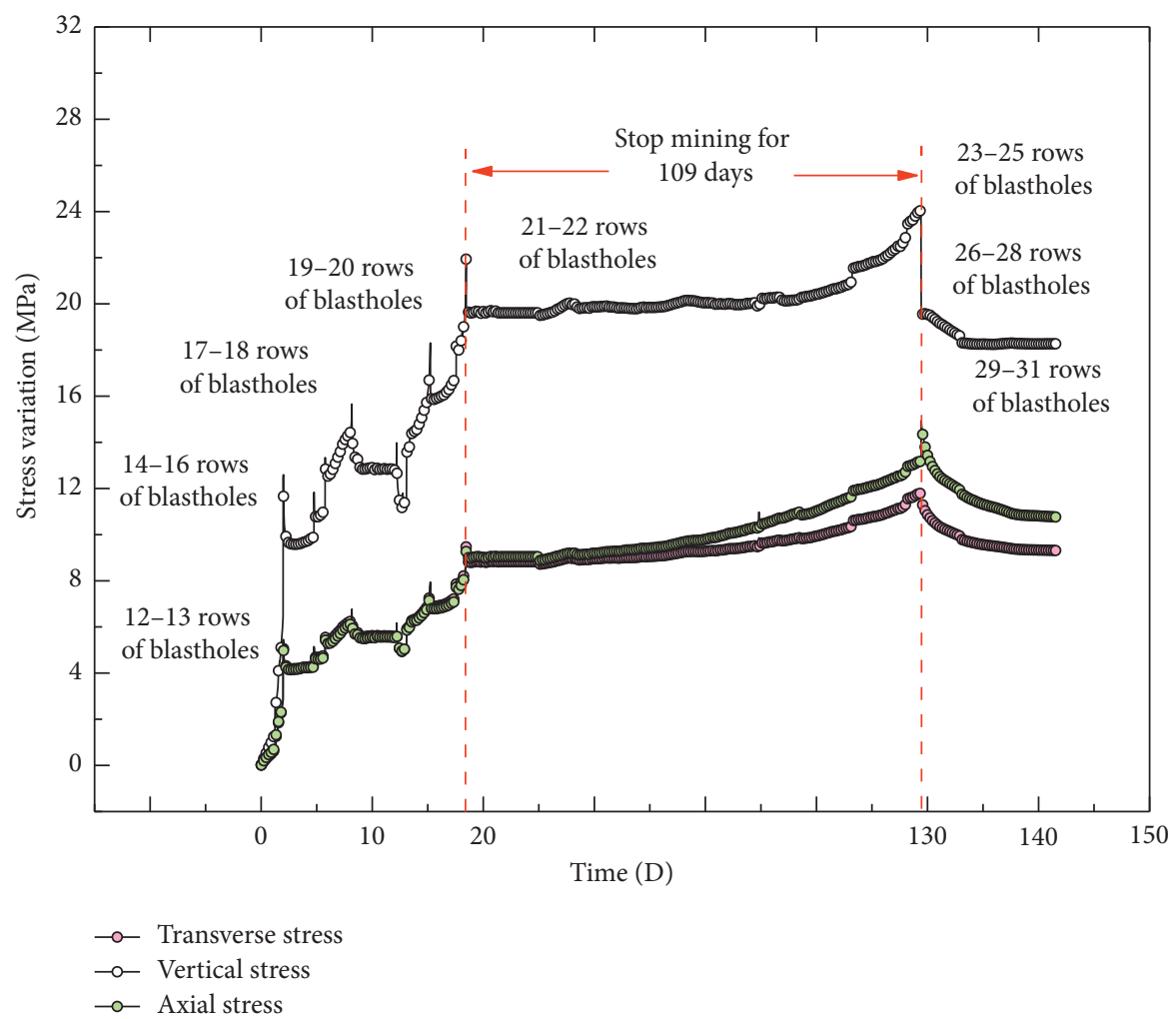

(d)

Figure 4: Dynamic monitoring data of stope mining-induced pressure in the whole process. (a) -325 horizontal section, (b) - 350 horizontal section, (c) -375 horizontal section, and (d) -400 horizontal section. 


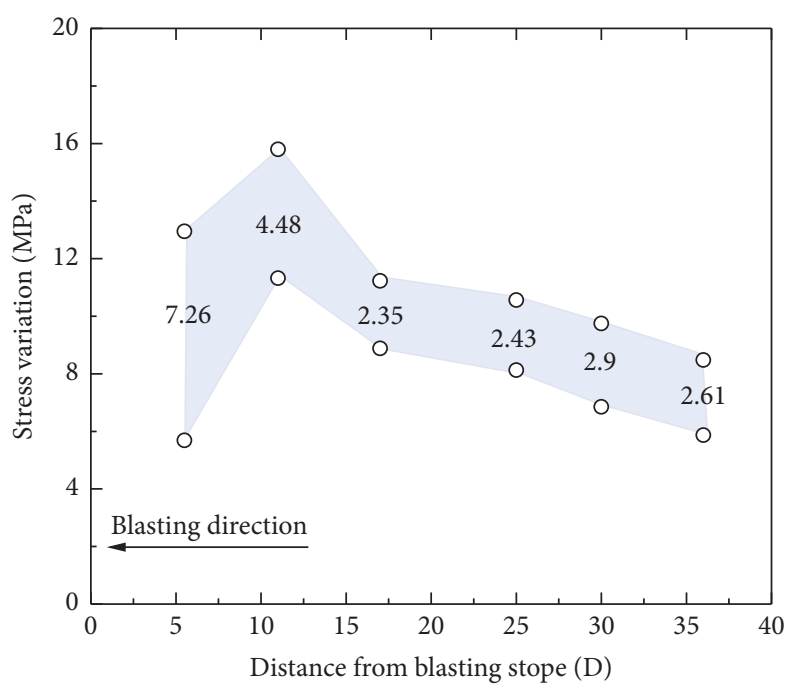

O -325 horizontal section vertical stress

(a)

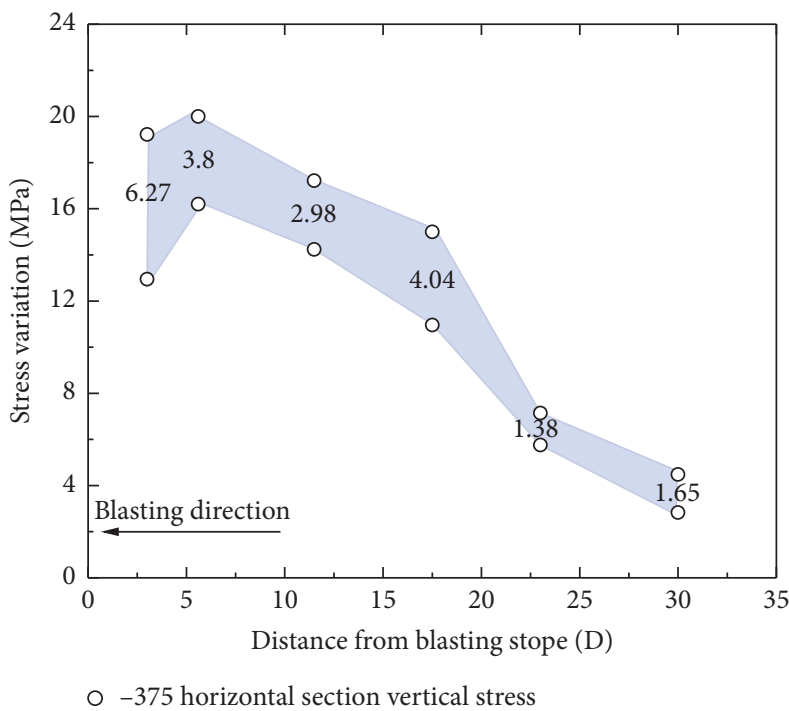

(c)

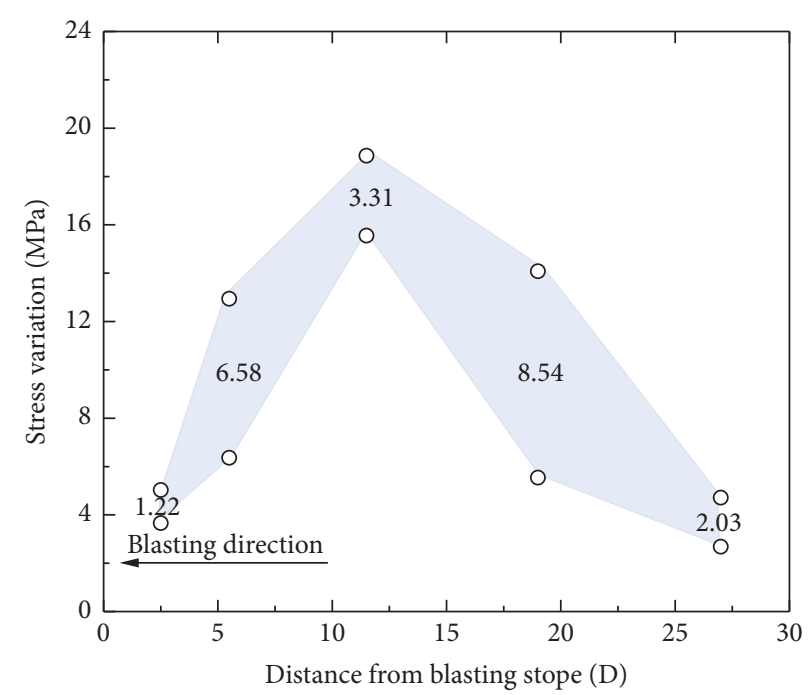

- -350 horizontal section vertical stress

(b)

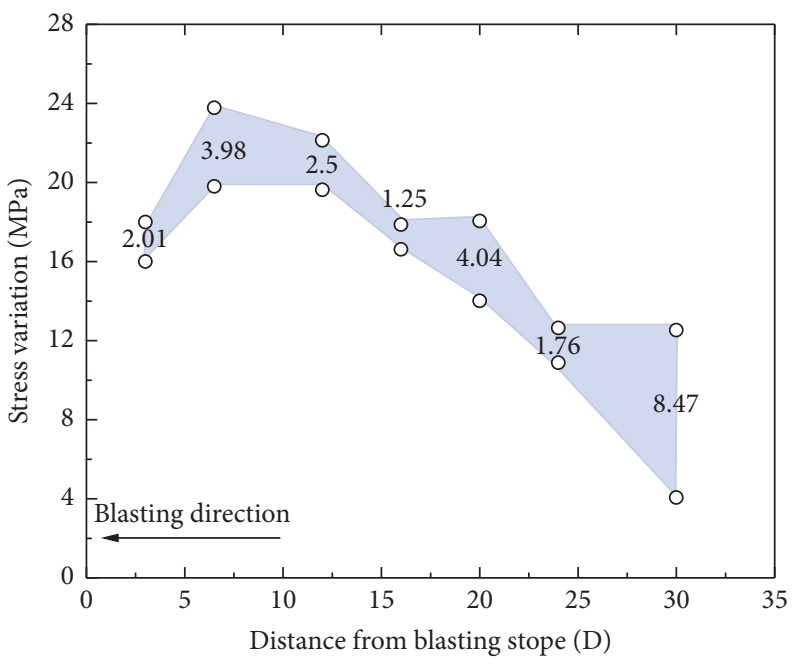

○ -400 horizontal section vertical stress

(d)

FiguRE 5: Stress jump of vertical stress under blasting. (a) -325 horizontal section, (b) -350 horizontal section, (c) -375 horizontal section, and (d) -400 horizontal section.

and $3.43 \mathrm{MPa}$, respectively, which is about $12 \%$ compared with the stable bearing stage. When the pressure is in the unloading stage, the pressure is released rapidly due to the rock fracture at the monitoring point, which shows the rapid stress falling down feature on the curve.

The three-dimensional stress peak values of the four horizontal segments are further selected as shown in Table 1, in which the vertical stress is higher than the horizontal stress, and the axial stress is higher than the transverse stress. The horizontal and axial horizontal average pressure measurement coefficients are 0.41 and 0.64 , respectively, it reflects that the direction of maximum horizontal principal stress in the stope is the direction of instrument installation, and the lateral pressure coefficient also increases with the increase of mining depth, indicating that the in situ stress field in the mining area is dominated by the horizontal tectonic stress and supplemented by vertical tectonic stress. In the development and design of roadway, the distribution of the maximum principal stress in the mining area should be considered, and the direction of the vein roadway should be consistent with the direction of the maximum principal stress or intersect at a small angle, to reduce the pressure on the roadway, which is of great significance to ensure the safety of the roadway.

3.2. Mining Stress Evolution. After the commissioning of the mining stress monitoring system, blasting work was started in 16-2\# stope. At the end of the high stope, the cutting groove is formed by one-time blasting with medium depth 
TABLE 1: Three-dimensional peak stress during the mining process.

\begin{tabular}{|c|c|c|c|c|c|c|}
\hline \multirow[t]{2}{*}{ Horizontal section $(\mathrm{m})$} & \multirow[t]{2}{*}{ Mining time (D) } & \multicolumn{3}{|c|}{ Three-dimensional peak stress $(\mathrm{MPa})$} & \multicolumn{2}{|c|}{$\begin{array}{l}\text { Side pressure } \\
\text { coefficient }\end{array}$} \\
\hline & & $\sigma_{z}$ & $\sigma_{x}$ & $\sigma_{y}$ & $\sigma_{x} / \sigma_{z}$ & $\sigma_{y} / \sigma_{z}$ \\
\hline-325 & 38 & 11.(15.80) & $5.04(5.92)$ & $9.58(10.56)$ & 0.45 & 0.85 \\
\hline-350 & 43 & 15.(18.86) & $5.21(6.04)$ & $6.96(8.52)$ & 0.34 & 0.45 \\
\hline-375 & 71 & $15 .(20.73)$ & $6.08(7.59)$ & $10.15(12.03)$ & 0.39 & 0.65 \\
\hline-400 & 129 & $23.7(19.8)$ & $11.85(11.22)$ & $15.03(13.33)$ & 0.50 & 0.63 \\
\hline
\end{tabular}

Note: the values in brackets are the stress jump under the influence of blasting.

hole, the cutting groove is taken as the free surface, and every three rows of blastholes are blasted as an operation unit. The upper horizontal section is horizontally ahead of the next horizontal section by an independent advance of one breaking, forming a downward trapezoidal face. When the first row of blastholes was mined in sequence with the last row of blastholes, the whole mining operation is completed. The distance between the mining point and monitoring point of four section and horizontal sections is selected as the horizontal coordinate, respectively, and the peak value of mining stress is taken as the vertical coordinate, as shown in Figure 5. Through the real-time monitoring of the mining stress in the process of high-level stope mining, the dynamic evolution law of the mining stress of the complete stope (stress rising stage, stable stage, and pressure relief stage) is obtained.

(1) I (stress rising stage): with the continuous advance of the working face, the distance between the working face and the monitoring point is decreasing, and the stress state of the rock mass at the monitoring point in front of the working face shows that the vertical stress and horizontal stress are increasing. With the continuous excavation of the ore body, the threedimensional mining stress state of the overlying strata of the roadway has changed, the vertical stress of the roadway is increasing, and the damage of the surrounding rock is accumulating, resulting in roof fall, rib spalling, and other problems.

(2) II (stable stage): as the working face continues to move forward, the distance between the working face and the monitoring point is further shortened, the stress on the surrounding rock at the monitoring point gradually reaches its peak, and the three-dimensional stress does not change significantly. At this stage, the surrounding rock force of the roadway is at its peak state, and the rock mass damage will continue to be accumulated. When the rock mass bearing stress limit is reached, the roadway is prone to deformation and failure.

(3) III (pressure relief stage): when the three-dimensional stress of the rock mass at the monitoring point reaches the peak value, it will decay rapidly as the working face moves forward again. At this time, the peak stress is transferred to the rock mass in front of the monitoring point, and the stress on the surrounding rock in the stope is released.
As shown in Figure 6, the monitoring results of the four horizontal sections show that the internal stress of some rock mass whose distance from the monitoring point to the working face is more than $15 \mathrm{~m}$ is increasing, and the peak stress is reached at about $5.5 \mathrm{~m}$ away from the monitoring point. When the distance is less than $5.5 \mathrm{~m}$, the stress decreases rapidly. Due to the presence of micropores and weak structural surfaces in the rock mass, and the repeated action of disturbing stress such as blasting and ore transportation, the rock will produce plastic strain, and the stress-strain response is not synchronized, which is manifested as the stress attenuation of the rock, as shown in Figures 5(a) and 5(d). In the abovementioned engineering disturbances, blasting has the most obvious impact on the stress state of the rock mass. Under the action of the blasting shock wave, the energy in the rock mass accumulates rapidly, and the stress rises rapidly in a short period of time, which is manifested in the phenomenon of stress jump on the monitoring data map. During the entire mining process, due to the advancement of the working face, the stress state of the overlying rock and the surrounding rock of the roadway has changed drastically. The destruction of rock cracks continues to develop, and the stress continues to change and redistribute. At the monitoring point, the rock mass has a temporary stress reduction phenomenon, but as the working face advances, the rock mass stress will rise again, as shown in Figure 5(c).

By further selecting the three-dimensional peak stress in three stages of stress rising stage, pressure bearing stable stage, and pressure relief stage, the time-space evolution law of the three-dimensional peak stress in 16-2 ${ }^{\#}$ stope is obtained, as shown in Figure 7. In terms of the horizontal height of different sections of stope, the three-dimensional stress evolution law of the four sublevel levels tends to be consistent in the whole mining process, which indicates that the change of mining stress can be more accurately reflected by the monitoring system. And in terms of the vertical peak stress in the four horizontal sections, as the mining depth increases by $25 \mathrm{~m}$, the vertical stress peak increases by an average of about $2.52 \mathrm{Mpa}$, which is equal to the weight of the overburden.

3.3. Mining Stress Transfer Model. Combined with the above analysis of the time-space evolution law of mining stress, to grasp the distribution state of surrounding rock stress in high stope, the vertical stress with the greatest influence on 


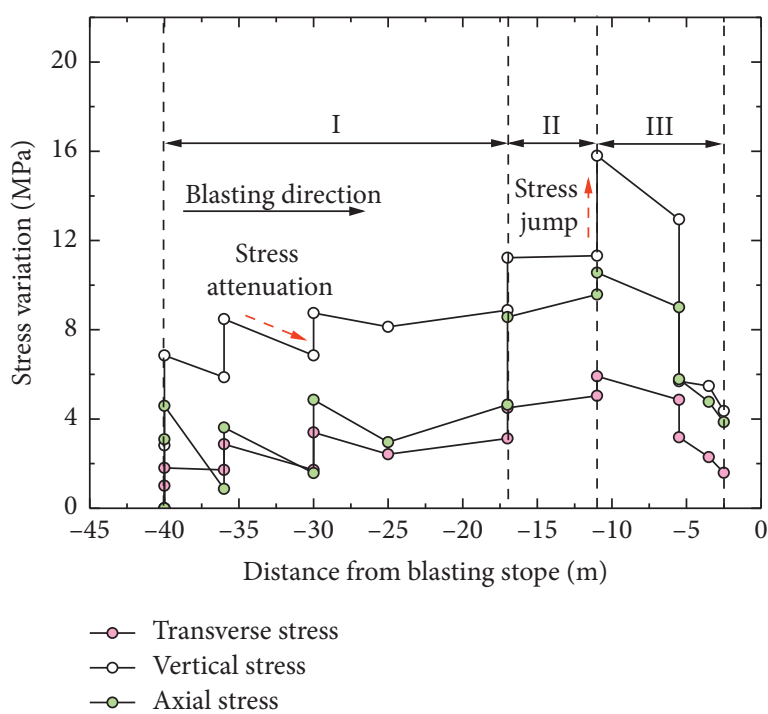

(a)

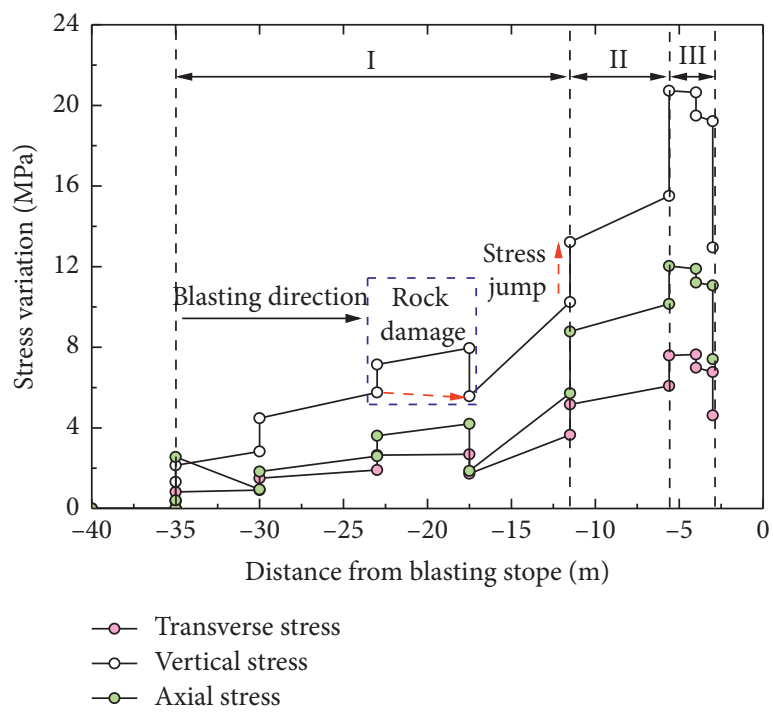

(c)

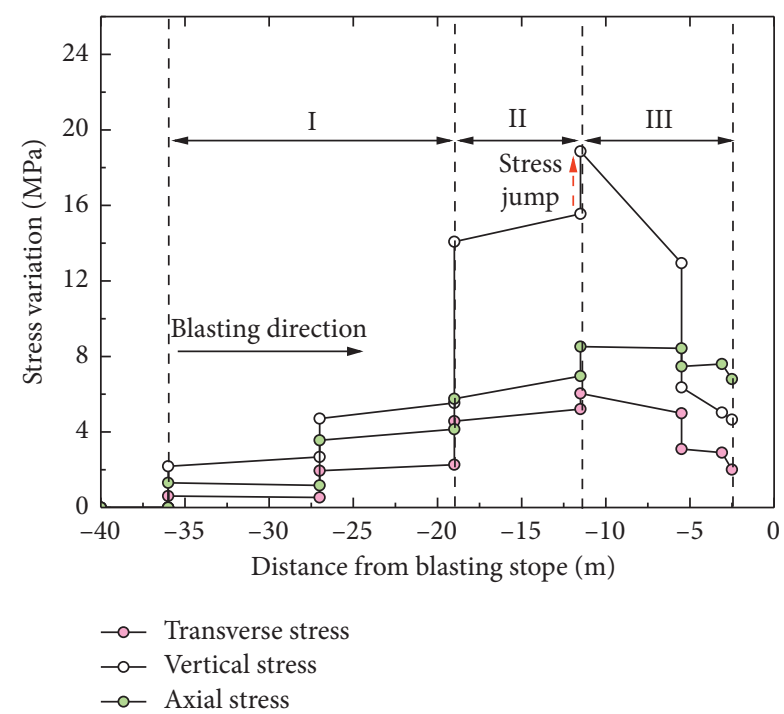

(b)

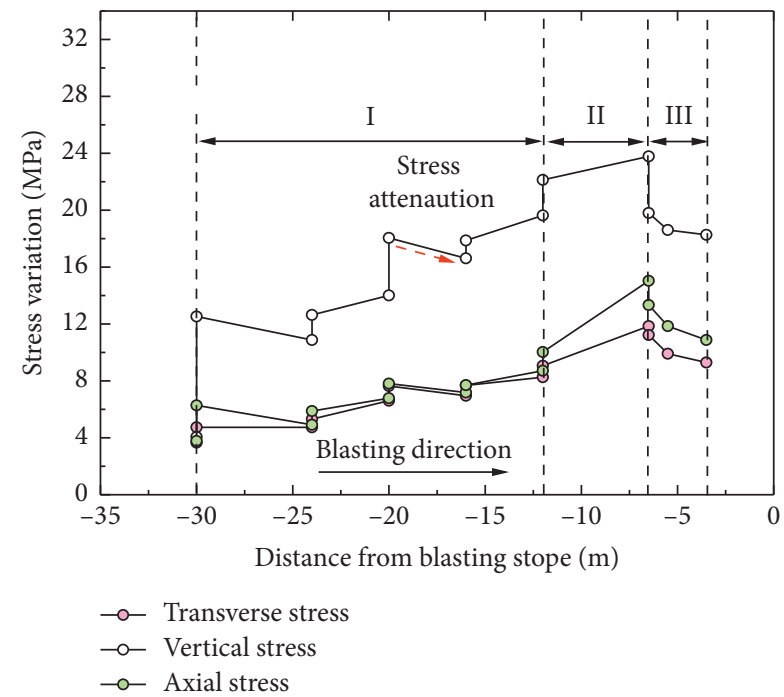

(d)

FIGURE 6: Evolution of horizontal mining stress in each horizontal section of 16-2 $2^{\#}$ stope. (a) -325 horizontal section, (b) -350 horizontal section, (c) -375 horizontal section, and (d) -400 horizontal section.

the three-dimensional stress is selected to make a scatter diagram, as shown in Figure 8. Through the polynomial fitting of the vertical stress scatter diagram by origin data analysis software, the fitting coefficients $R^{2}$ of $-325 \mathrm{~m}$,
$-350 \mathrm{~m},-375 \mathrm{~m}$, and $-400 \mathrm{~m}$ sections are $0.79,0.86,0.89$, and 0.94 , respectively, and good fitting results are obtained. The fitting formula is as follows:

$$
\sigma_{z}=\left\{\begin{array}{l}
1.430 \times 10^{-3} L^{3}-0.108 L^{2}+2.124 L+4.425(-325 \text { Horizontal section }), \\
3.690 \times 10^{-3} L^{3}-0.229 L^{2}+3.612 L-4.332(-350 \text { Horizontal section }) \\
1.740 \times 10^{-3} L^{3}-0.096 L^{2}+0.845 L+15.329(-375 \text { Horizontal section }) \\
1.710 \times 10^{-3} L^{3}-0.116 L^{2}+1.618 L+14.535(-400 \text { Horizontal section) }
\end{array}\right.
$$

As shown in Figure 8, with the mining of the ore body, the stress is mainly borne by the pillar, and the vertical stress of $-325 \mathrm{~m}$ horizontal section reaches the peak value first, and the stress peak of $-350 \mathrm{~m}$ horizontal section, $-375 \mathrm{~m}$ 


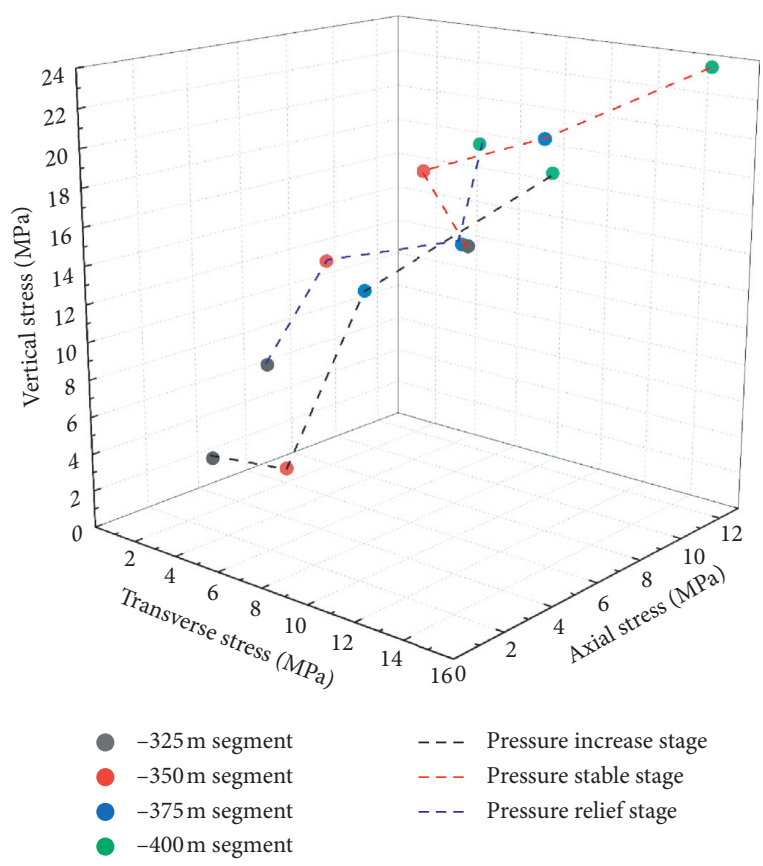

FIGURE 7: Time-space evolution process of three-dimensional stress peak.

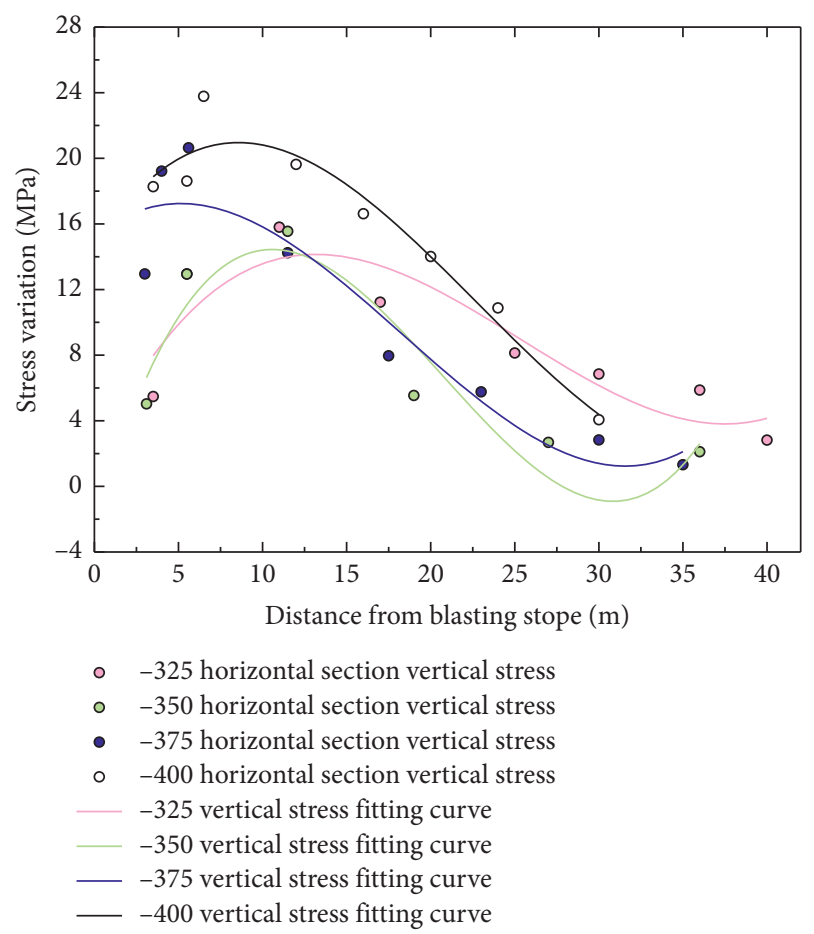

FIGURE 8: The law of horizontal vertical stress variation with depth in each section of stope.

horizontal section, and $-400 \mathrm{~m}$ horizontal section is reached in turn. The surrounding rock of the roadway presents "layered ladder" stress transfer, and it is "layered ladder" stress transfer from top to bottom. The formula can be used to estimate the numerical range of the vertical stress $\sigma_{z}$ of the surrounding rock of the roadway when the roadway is buried in different depths and excavated to a certain position in the stope mining process, which provides a certain guidance for the safety production of the mine.

\section{Comparative Analysis of Numerical Simulation}

On the basis of the abovementioned in situ experimental analysis, to further grasp the stress and displacement of the surrounding rock of the roadway during the mining process of the large structure parameter stope, the $16-2^{*}$ stope of Lilou Iron Mine was selected and combined with the numerical software FLAC3D authenticating.

4.1. Model Construction and Mechanical Parameter Selection. Through a comprehensive analysis of the occurrence characteristics of the Lilou iron ore body, the location of the excavated ore body, and the scope of the excavation influence, a three-dimensional calculation model was established. The size of the model is $400 \mathrm{~m} \times 180 \mathrm{~m} \times 300 \mathrm{~m}$, and the model height is $-200 \mathrm{~m} \sim 500 \mathrm{~m}$; the ore body is located between $-400 \mathrm{~m}$ and $-300 \mathrm{~m}$ in elevation. In the process of establishing the ore body model, the MIDAS-GTS software was used for modeling without considering the small-scale geological structure surface with little impact on the mining area. The numerical model is composed of a hanging wall, ore body, footwall, and filling body. The $X$ direction is perpendicular to the ore body strike, the $Y$ direction is along the ore body strike, and $Z$ is the vertical direction. Geotechnical engineering numerical simulation software is used to construct the model and mesh. It is divided into 77,919 units and 55,406 nodes, as shown in Figure 9. Considering the stope structure parameters of Lilou Iron Mine are large, the stope is mined by layers, and the mining time of each section level varies greatly; the mine pillars to be excavated are subdivided according to the horizontal section. Combined with the actual situation of on-site mining, the model excavation calculation is carried out in 9 times. The internal excavated ore body model is shown in Figure 10.

This simulation takes into account the actual situation of the site. To maximize the restoration of the site conditions and reflect the time-space effect during excavation, four sublevel minings are designed, and there is a certain time difference in the mining progress; the excavation of the ore body starts from (1) and ends at (9), as shown in Figure10(b). Figure 10(a) shows that the stope adjacent to 16-2 ${ }^{\#}$ stope has been mined and filled with backfill. The rock mass in the project area is sampled, and dolomite marble, specularite, and chlorite schist are processed into standard test pieces for physical and mechanical properties tests. Limited to space, some test results are shown, as shown in Figure 11. The rock parameters are determined by combining the results of joint surface investigation on the project site, and the reduction schemes of rock type, rock classification RMR value, GSI value of rock structure surface, etc. The mechanical parameters obtained from the test are weakened, as shown in Table 2. 


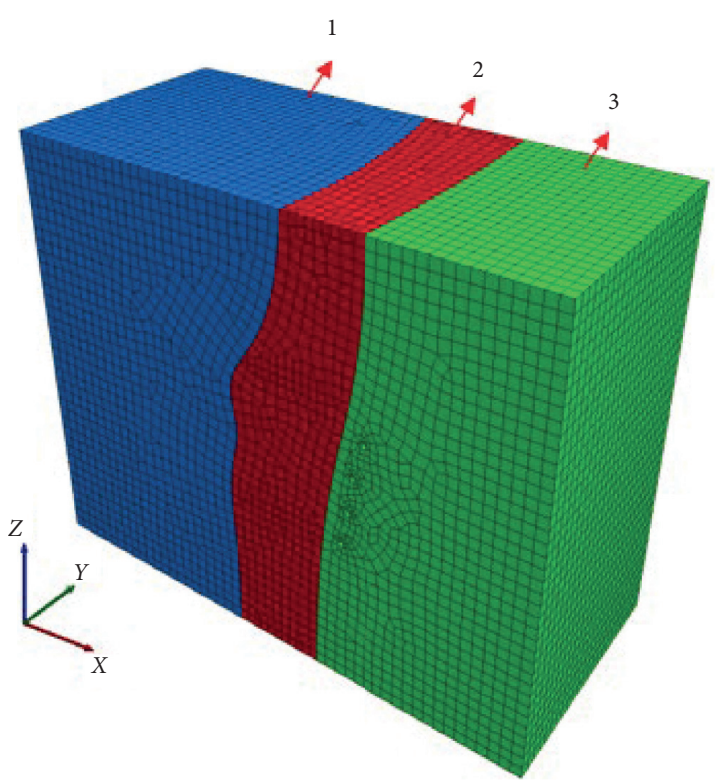

(a)

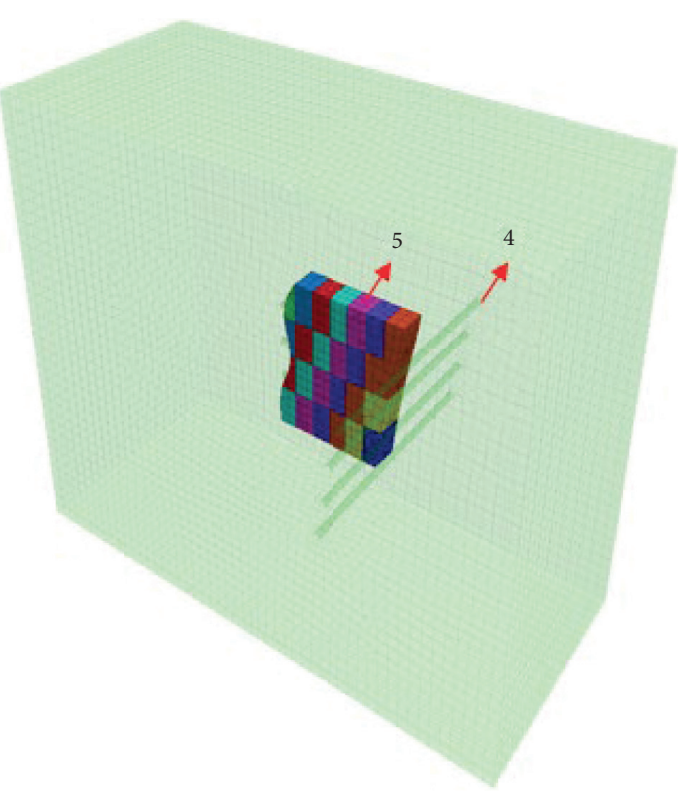

(b)

Figure 9: Calculation model: (1) hanging wall, (2) ore body, (3) lower wall, (4) retaining roadways along goaf, and (5) stope.

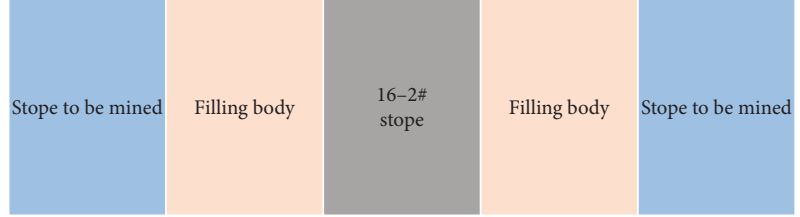

(a)

\begin{tabular}{|l|l|l|l|l|l|l|}
\hline (1) & (2) & (3) & (4) & (5) & (6) & -325 \\
\hline (2) & (3) & (4) & (5) & (6) & (7) & -350 \\
\hline (3) & (4) & (5) & (6) & (7) & $(8)$ & -375 \\
\hline (4) & (5) & (6) & (7) & (8) & (9) & -400 \\
\hline
\end{tabular}

(b)

FIgURE 10: Schematic diagram of stope mining sequence. (a) Layout along the ore body strike. (b) Vertical ore body strike layout.

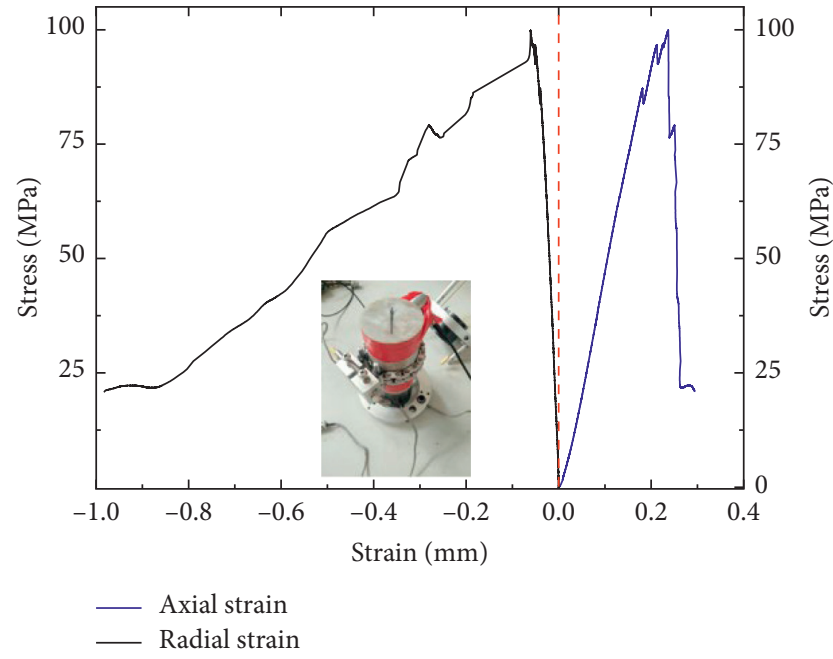

(a)

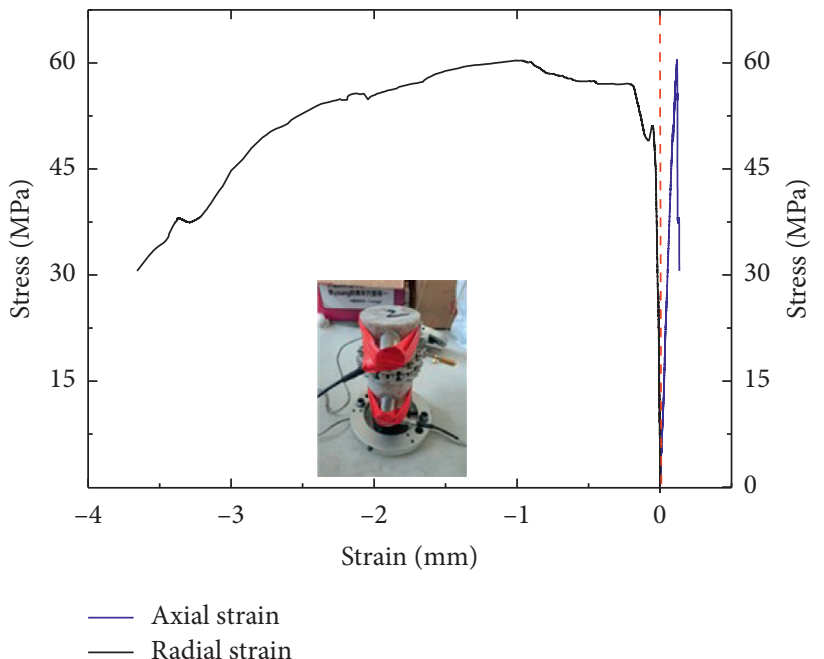

(b)

Figure 11: Uniaxial compression experiment of dolomite marble. (a) Dolomite marble sample 1. (b) Dolomite marble sample 2. 
TABLE 2: Mechanical parameters of Lilou Iron Mine-related rock masses.

\begin{tabular}{lccccccc}
\hline Rock mass & $\begin{array}{c}\text { Density } \\
\left(\mathrm{kg} / \mathrm{m}^{3}\right)\end{array}$ & $\begin{array}{c}\text { Elastic modulus } \\
(\mathrm{GPa})\end{array}$ & $\begin{array}{c}\text { Poisson's } \\
\text { ratio }\end{array}$ & $\begin{array}{c}\text { Cohesion } \\
(\mathrm{MPa})\end{array}$ & $\begin{array}{c}\text { Friction angle } \\
\left({ }^{\circ}\right)\end{array}$ & $\begin{array}{c}\text { Tensile strength } \\
(\mathrm{MPa})\end{array}$ & $\begin{array}{c}\text { Compressive strength } \\
(\mathrm{MPa})\end{array}$ \\
\hline $\begin{array}{l}\text { Dolomite } \\
\text { marble }\end{array}$ & 2838 & 21.135 & 0.234 & 1.86 & 42.38 & 0.747 & 31.760 \\
$\begin{array}{l}\text { Quartz } \\
\text { specularite }\end{array}$ & 3487 & 25.119 & 0.202 & 3.72 & 41.76 & 2.765 & 45.924 \\
$\begin{array}{l}\text { Chlorite schist } \\
1: 6 \text { filling body }\end{array}$ & 2682 & 11.260 & 0.258 & 1.53 & 43.12 & 0.529 & 12.624 \\
\hline
\end{tabular}

4.2. Constitutive Selection and Boundary Condition Setting. The rock mass parameters used in this model calculation are dolomite, basalt, chlorite, schist, and cemented infill. According to engineering experience, the Mohr-Coulomb yield condition is generally used as the constitutive calculation. The expression is

$$
f_{s}=\sigma_{1}-\sigma_{3} \frac{1+\sin \varphi}{1-\sin \varphi}-2 c \sqrt{\frac{1+\sin \varphi}{1-\sin \varphi}} .
$$

In the formula, the sign stipulates as follows: tensile stress is "positive," compressive stress is "negative," $\sigma_{1}$ and $\sigma_{3}$ stand for maximum and minimum principal stresses, and $c$ and $\varphi$ stand for cohesion and internal friction angle. When $f_{s}>0$, the material will undergo shear failure. In the state of tensile stress, if the tensile stress exceeds the tensile strength of the material, that is, when $\sigma_{3} \geq \sigma_{T}$, the material will undergo tensile failure.

The upper boundary of the model is loaded with 4.9 $\mathrm{MPa}$, and the lower boundary is fixed. The horizontal constraint boundary of the ore body strike (i.e., $Y$ direction) is imposed, and the boundary displacement of ore body dip direction (i.e., $X$ direction) is fixed. Because the initial in situ stress field has an important influence on the reliability and accuracy of the numerical simulation calculation results, the field-measured in situ stress data are used in this model calculation. The in situ stress measurement results of Lilou Iron Mine show that the direction of the maximum principal stress is $\mathrm{NE}$, and the regression equations of the maximum horizontal principal stress and the minimum horizontal principal stress varying with depth are applied as boundary stress conditions [26]. The equation is as follows:

$$
\begin{gathered}
\sigma_{\max }=-0.4842+0.0498 H(\mathrm{MPa}), \\
\sigma_{\min }=-1.2066+0.0255 H(\mathrm{MPa}) .
\end{gathered}
$$

4.3. Analysis of Numerical Simulation Results. Combined with the actual monitoring results, it can be seen that the vertical stress of the mining stress has the greatest impact on the surrounding rock. Therefore, the vertical stress of the three stages of simulated mining is selected for analysis, and the results are shown in Figure 12.

Figure 12 shows the stress distribution cloud diagram of the vertical stress of $16-2^{\#}$ stope during the entire mining process. From Figure 12(a), it can be seen that in the early stage of mining, affected by the weight of the rock mass, the vertical stress increases from top to bottom, and a certain pressure relief area is formed above the roof of the roadway along the vein. Figure 12(b) shows that with the mining of the ore body, the area of the goaf gradually increases, the stress continuously redistributes, and an obvious pressure relief area is formed above the goaf; the roof of the minedout area is mainly compressed, and the pressure range is $0 \sim$ $2 \mathrm{MPa}$; part of the rock mass is subjected to a tensile stress of 1.05 $\mathrm{MPa}$, which is less than the tensile strength of the rock mass itself. The stress of the rock mass above the mining drift in the mining direction gradually increases to the peak stress, which shows the spatial transfer mode of the vertical stress with the mining of the ore body, which is consistent with the actual monitoring results. The stress concentration of the part of the bottom of the goaf and the surrounding rock of the upper wall is $22.25 \mathrm{MPa}$, which is a factor that causes the failure of the bottom structure of the goaf. Figure 12(c) shows that with the completion of the mining work, pressure relief zones are formed on the upper and lower sides of the mined-out area, and the surrounding rock stress redistribution is completed. The range of compressive stress along the vein roadway is $6-12 \mathrm{MPa}$, which is about $50 \%$ higher than that in the initial stage of mining, which is also the reason for the problems of roof fall and rib spalling in the actual production process. Figure 12(d) shows that the roof and floor of the goaf mainly produce tensile failure, and the upper and lower walls of the goaf mainly produce shear damage, especially the surrounding rock of the lower wall, which produces a large range of shear damage, so the lower wall the roadway in the surrounding rock should be strengthened to support.

To make a more intuitive comparison with the field monitoring data, the three-dimensional stress data of $-325 \mathrm{~m},-350 \mathrm{~m},-375 \mathrm{~m}$, and $-400 \mathrm{~m}$ horizontal sections are extracted, and the evolution law of mining stress in the whole mining process is obtained, as shown in Figure 13.

The numerical simulation result in Figure 13 shows that the four-stage horizontal stope process of $16-2^{\#}$ stope has similar regularity to the actual measurement, and it is also divided into three stages, namely, I (stress rising stage), II (stable stage), and III (pressure relief stage). The measured result vertical stress peak value reaches $23.78 \mathrm{MPa}$, the simulation result vertical stress peak value reaches 17.71 MPa, while the measured horizontal stress peak value reaches $15.03 \mathrm{MPa}$, and the simulated result horizontal stress peak value reaches $4.15 \mathrm{MPa}$. Compared with the measured 


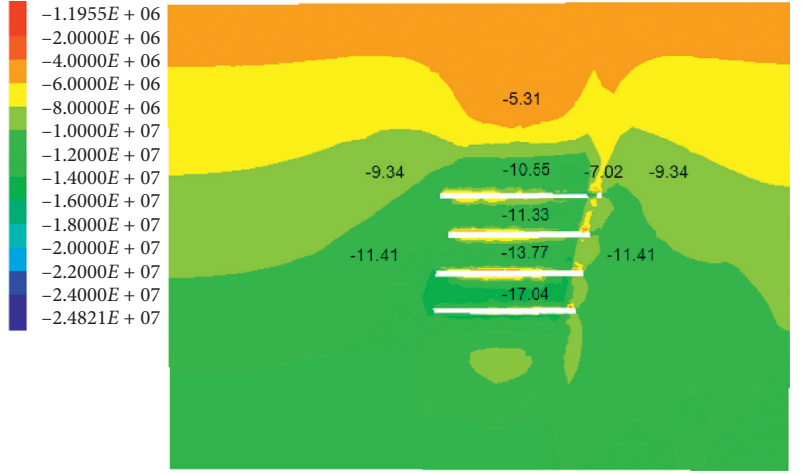

(a)

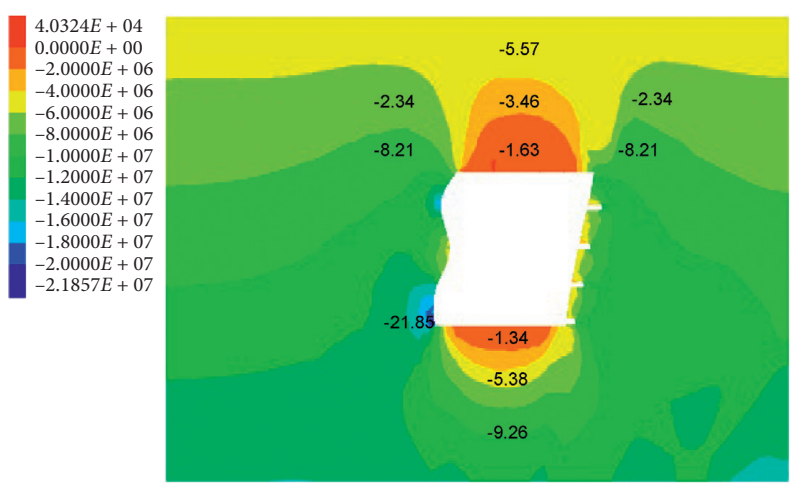

(c)

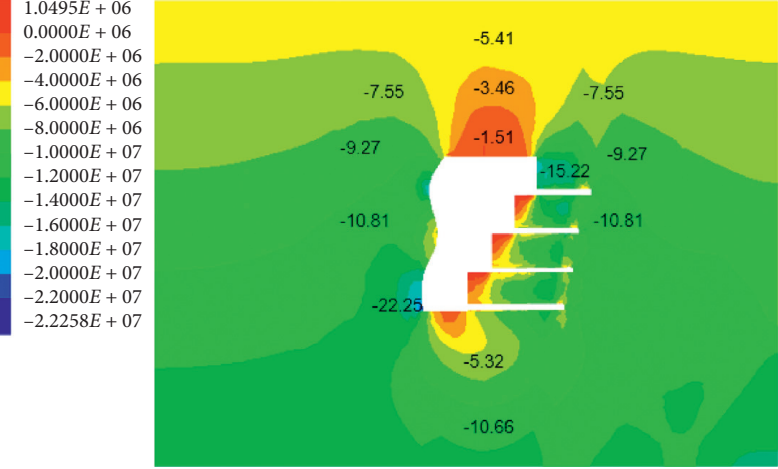

(b)
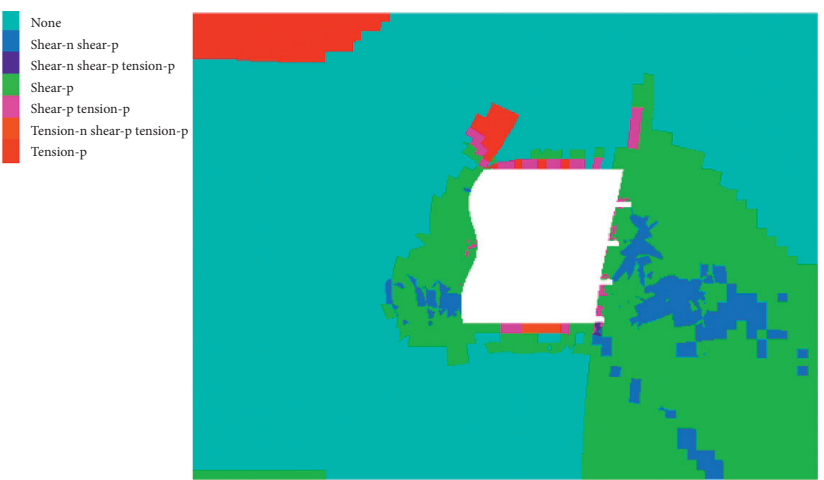

(d)

FIGURE 12: Vertical mining stress evolution cloud diagram: (a) early mining, (b) mining, (c) mining is complete, and (d) plastic zone.
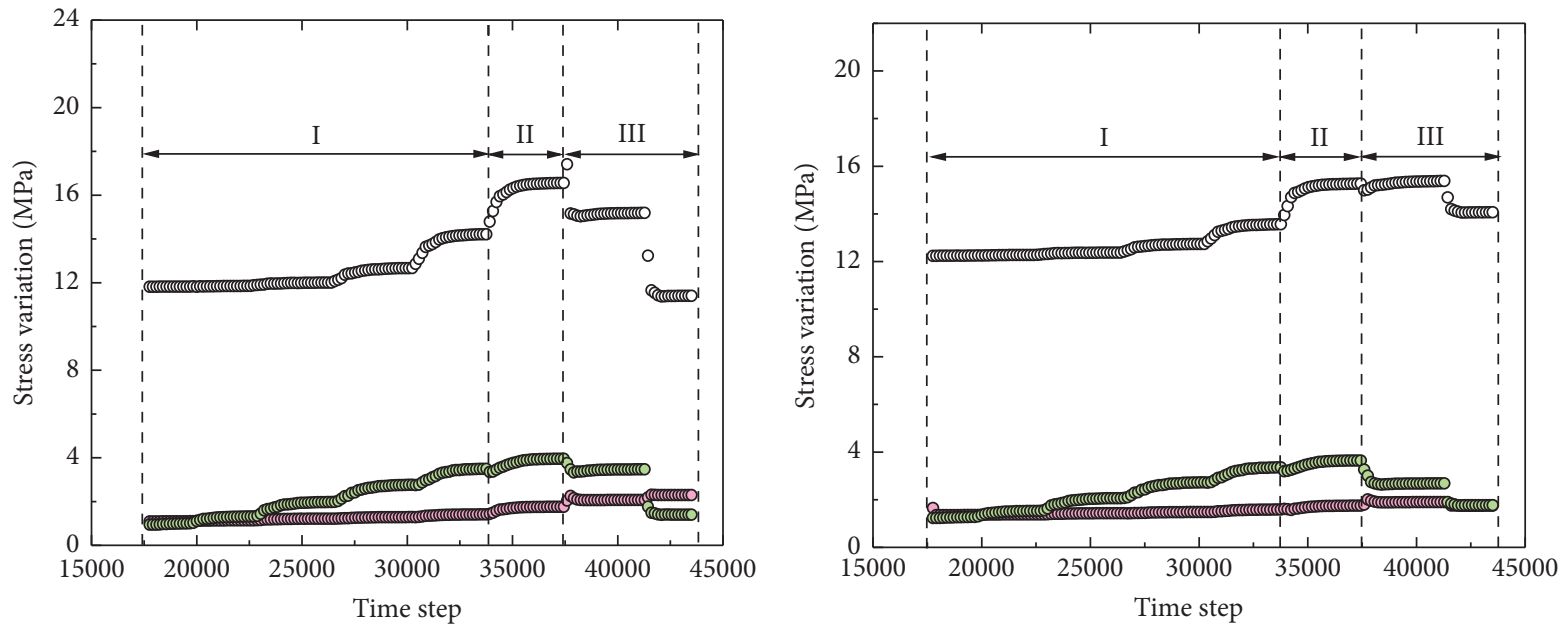

- Transverse stress

- Transverse stress

- Vertical stress

- Vertical stress

- Axial stress

- Axial stress

(a)

(b)

Figure 13: Continued. 


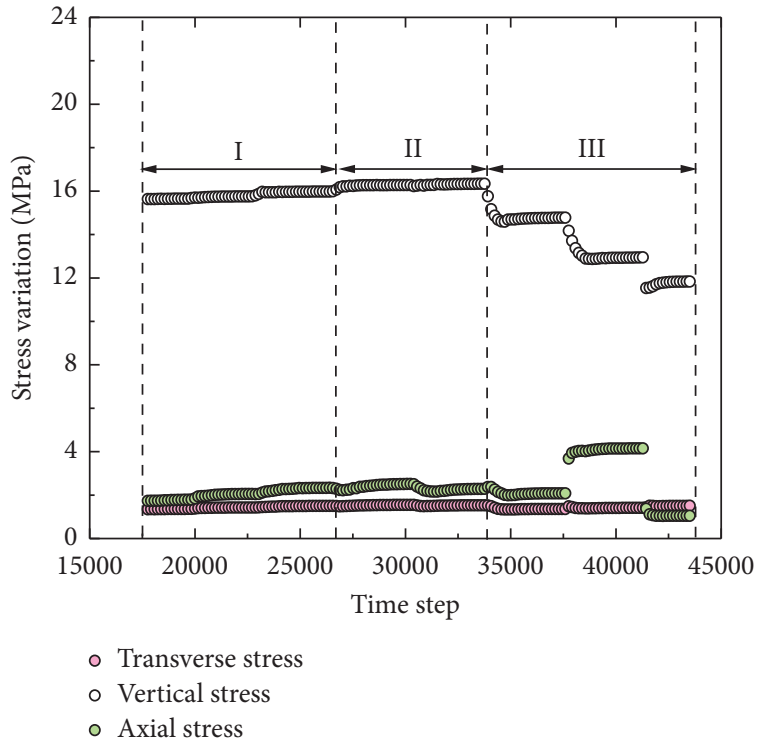

(c)

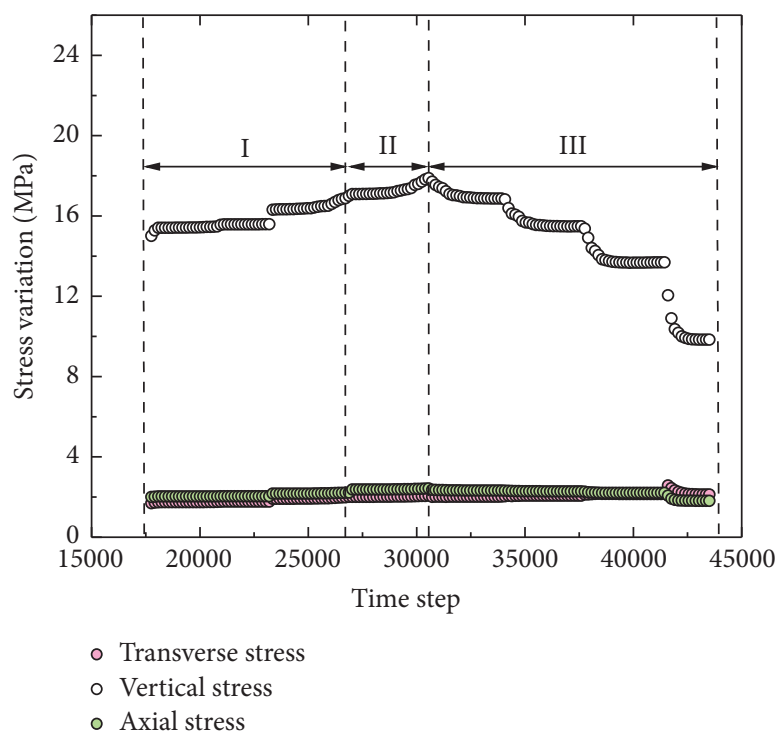

(d)

Figure 13: Numerical simulation results: (a) -325 horizontal section, (b) -350 horizontal section, (c) -375 horizontal section, and (d) -400 horizontal section.

results, the numerical simulation results are slightly smaller, but there is no order of magnitude difference between them; therefore, the evolution law of mining stress based on numerical simulation is reasonable, and the reliability of the stress measurement method used in this paper is verified.

\section{Conclusion}

Based on the mining stress in-site measurement, a new monitoring system of mining stress is adopted in this work to study the temporal and spatial evolution of surrounding rock stress under the influence of mining stress. A threedimensional numerical model is established, and the simulation results are in good agreement with the measured results. The following conclusions can be drawn:

(1) Through the mining-induced pressure in-site monitoring of the $16-2^{\#}$ stope of Lilou Iron Mine, the evolution of mining-induced pressure in the subsequent filling mining method of the high stage empty pit is obtained. The force process of the surrounding rock of the mining is roughly divided into three stages: I (stress rising stage),II (stable stage), and III (pressure relief stage), and the evolution law is universal. The stress is gradually rising (outside about $19 \mathrm{~m}$ ), the stability stage (about $6.5 \mathrm{~m}-19 \mathrm{~m}$ ), and the pressure relief stage $(3.5 \mathrm{~m}-6.5 \mathrm{~m})$. The mining stress in the surrounding rock is transferred from the top to bottom.

(2) The mining stress transfer model of stope is constructed, and the vertical stress variation with depth is fitted, the fitting coefficient $R^{2}$ of $-325 \mathrm{~m},-350 \mathrm{~m}$, $-375 \mathrm{~m}$, and $-400 \mathrm{~m}$ horizontal section is $0.79,0.86$, 0.89 , and 0.94 , and the fitting result is good. The variation can not only estimate the value range of vertical stress when the roadway with different buried depth is excavated to a certain position but also can predict the change value of mining stress in the next deep mining. The result is of practical significance for the areas with the possibility of surrounding rock deformation and failure to make protection guidance in advance, and for the timely treatment of sudden accidents.

(3) By constructing the three-dimensional numerical model and carrying out distributed excavation simulation, the time-space evolution of mining stress in the stope was obtained. Compared with the in-site measurement results, the two results show high consistency, and the effectiveness of numerical simulation is verified; this will provide reference for the same type and similar mining method.

\section{Data Availability}

The data used to support the findings of this study are available from the corresponding author upon request.

\section{Conflicts of Interest}

The authors declare no conflicts of interest.

\section{Acknowledgments}

The authors would like to thank Mr. Wei Xiaoming of the Beijing Mining General Institute for his guidance in the research and Mr. Zhang Lixin of Anhui Mining Development Co., Ltd. for his active cooperation in the field work. This article was funded by the Fundamental Research Funds of the Central Universities (06500182) and the open fund 
from State Key Laboratory of Coal Resources in Western China (SKLCRKF20-07).

\section{References}

[1] H. Xie, H. Zhou, J. Liu et al., "Mining-induced mechanical behavior in coal seams under different mining layouts," Meitan Xuebao/Journal China Coal Society, vol. 36, pp. 1607-1074, 2011.

[2] M. Zhang, L. Dou, H. Konietzky, Z. Song, and S. Huang, "Cyclic fatigue characteristics of strong burst-prone coal: experimental insights from energy dissipation, hysteresis and micro-seismicity," International Journal of Fatigue, vol. 133, Article ID 105429, 2020.

[3] S. Zhu, Y. Ma, F. Jiang et al., "Mechanism of rock burst in the bottom coal seam of super high seam with overall slippage and instability," Caikuang Yu Anquan Gongcheng Xuebao/Journal Mining Safety Engineering, vol. 38, p. 3140, 2021.

[4] Z. Song, Y. Wang, H. Konietzky, and X. Cai, "Mechanical behavior of marble exposed to freeze-thaw-fatigue loading," International Journal of Rock Mechanics and Mining Sciences, vol. 138, Article ID 104648, 2021.

[5] C. Zhu, Y. Yuan, C. Yuan, W. Wang, and C. Meng, "Stability evaluation and layout of surrounding rock in deep large section tunnel," Caikuang Yu Anquan Gongcheng Xuebao/ Journal Min Saf Eng, vol. 37, pp. 11-22, 2020.

[6] G. Zhou, Y. Li, Q. Zhang et al., "Research on monitoring technique and evolution law of the disturbance stress in Chensilou Colliery," Meitan Xuebao/Journal China Coal Soc, vol. 41, pp. 1087-1092, 2016.

[7] X. Hao, Y. Wei, K. Yang et al., "Anisotropy of crack initiation strength and damage strength of coal reservoirs," Petroleum Exploration and Development, vol. 48, no. 1, pp. 243-255, 2021.

[8] X. Hao, W. Du, Y. Zhao et al., "Dynamic tensile behaviour and crack propagation of coal under coupled static-dynamic loading," International Journal of Mining Science and Technology, vol. 30, no. 5, pp. 659-668, 2020.

[9] N. Liu, C. Zhang, X. Chen, J. Hou, and W. Chu, "Monitoring and characteristics study of stress evolution of surrounding rock during deep tunnel excavation," Yanshilixue Yu Gongcheng Xuebao, vol. 30, pp. 1729-1737, 2011.

[10] Y. Li, Z. Liu, L. Qiao, and S. Fu, "Stress monitoring techniques based on the twin temperature compensation method of digital CSIRO," International Journal of Advanced Engineering Science, vol. 20, pp. 18-26, 2018.

[11] H. Kang, "Stress distribution characteristics and strata control technology for roadways in deep coal mines," International Journal of Coal Science \& Technology, vol. 41, pp. 12-17, 2013.

[12] Z. Song, H. Konietzky, and M. Herbst, "Drawing mechanism of fractured top coal in longwall top coal caving," International Journal of Rock Mechanics and Mining Sciences, vol. 130, Article ID 104329, 2020.

[13] J. Lou, F. Gao, J. Yang et al., "Characteristics of evolution of mining-induced stress field in the longwall panel: insights from physical modeling," International Journal of Coal Science \& Technology, vol. 24, 2021.

[14] G. Xie, J. Li, L. Wang, and Y. Tang, "Mechanical characteristics and time and space evolvement of stress shell in stope floor stratum," Meitan Xuebao/Journal of the China Coal Society, vol. 43, pp. 52-61, 2018.

[15] A. M. Suchowerska, R. S. Merifield, and J. P. Carter, "Vertical stress changes in multi-seam mining under supercritical longwall panels," International Journal of Rock Mechanics and Mining Sciences, vol. 61, pp. 306-320, 2013.

[16] M. Zhang, F. Jiang, G. Chen, Z. Jiao, H. Hu, and B. Chen, “A stope stress transfer model based on the motion state of thick and hard rock strata and its application," Yanshilixue Yu Gongcheng Xuebao/Chinese International Journal of Rock Mechanics Engineering, vol. 39, pp. 1396-1407, 2020.

[17] R. Peng, X. Meng, G. Zhao et al., "The evolvement law of deep circular roadway secondary bearing structure "time-space" integration," Caikuang Yu Anquan Gongcheng Xuebao/International Journal of Mining Science and Technology, vol. 33, pp. 779-786, 2016.

[18] H. Xie, F. Gao, and Y. Ju, "Research and development of rock mechanics in deep ground engineering," Yanshilixue $Y u$ Gongcheng Xuebao/Chinese International Journal of Rock Mechanics Engineering, vol. 34, pp. 2161-2178, 2015.

[19] L. Wang, H. Zhou, T. Rong, and W. Ren, "Stress field evolution aw and disturbance characteristic of coalat depth under mining," Yanshilixue Yu Gongcheng Xuebao/Chinese International Journal of Rock Mechanics Engineering, vol. 38, pp. 2944-2954, 2019.

[20] Y. Guo, H. Zhou, T. Rong et al., "Disturbance characteristics of deep coal mass under the mining stress path," Meitan Xuebao/Journal of the China Coal Society, vol. 43, pp. 30723079, 2018.

[21] Y. Pang, G. Wang, and B. Li, "Stress path effect and instability process analysis of overlyingstrata in deep stopes," Yanshilixue Yu Gongcheng Xuebao/Chinese International Journal of Rock Mechanics Engineering, vol. 39, pp. 682-694, 2020.

[22] M. Zhang, F. Jiang, J. Wang, Z. Hu, and J. Liu, "Space-time regularity of roadway deformation under disturbance of several coal seams in ultra-deep mines," Caikuang Yu Anquan Gongcheng Xuebao/Journal Mining Safety Engineering, vol. 35, pp. 229-237, 2018.

[23] Y. Wang, W. K. Feng, and C. H. Li, "On anisotropic fracture and energy evolution of marble subjected to triaxial fatigue cyclic-confining pressure unloading conditions," International Journal of Fatigue, vol. 134, Article ID 105524, 2020.

[24] Y. Wang, C. H. Li, H. Liu, and J. Q. Han, "Fracture failure analysis of freeze-thawed granite containing natural fracture under uniaxial multi-level cyclic loads," Theoretical and Applied Fracture Mechanics, vol. 110, Article ID 102782, 2020.

[25] Y. Li, Z. Wang, L. Qiao, M. Cai, and Q. Li, "Development of CSIRO cell with the compromised application of instantaneous data-logging, no-power data-connection and twin temperature compensation techniques," Yanshilixue Yu Gongcheng Xuebao/Chinese Journal of Rock Mechanics and Engineering, vol. 36, pp. 1479-1487, 2017.

[26] Y. Hu, C. Li, W. Luo, R. Liu, and B. Huang, "Study on the insitu stress measurement and distribution law in the Li lou mining area," IOP Conference Series: Earth and Environmental Science, vol. 252, 2019. 